\title{
An Examination of Veridicality in Verbal Protocols of Language Learners
}

\author{
Patriann Smith \\ Childhood Education and Literacy Studies, University of South Florida, Tampa, FL, United States \\ James R. King \\ Childhood Education and Literacy Studies, University of South Florida, Tampa, FL, United States
}

\begin{abstract}
In this paper, we concentrate on veridicality within verbal protocols when they are used to examine the reading processes of language learners (LLs). Eight methodological recommendations and considerations for verbal protocols proposed in Ericsson and Simon $(1984 ; 1993)$ are used to review 20 LL reading research studies that utilized verbal protocols in research from the previous decade. Issues related to errors of commission and omission as well as errors associated with language as an inherent variable within $L L$ verbal protocols are then examined. Among the implications for research is the need to reconceptualize the theoretical basis for elicitation of LLs' verbal protocols during the reading process.
\end{abstract}

Index Terms - veridicality, verbal protocols, verbal reports, language learners, second language learners, think-alouds

\section{INTRODUCTION}

Over the past decade, trends have been noted towards the re-conceptualization of second language acquisition (SLA). This trend results from an acknowledgement of the interaction between cognitively-based theories and socially-oriented approaches (Grabe, 2009), and their impact on language learning. Proponents of a socially-based theory favor a dialectical approach (Lantolf, 2007), in which constructs originally considered contrary to each other (e.g., individual/social, learning/acquisition) are integrated into one inquiry space in order to facilitate investigation of language, communication and second language learning. Embedded within sociocultural accounts of language learning are cognitivists' (Ellis \& Larsen-Freeman, 2006) conceptualizations of "superposition." In a superposition, dichotomous and paradoxical conceptions of second language emergence and acquisition relinquish their roles as "polar opposites" (Ellis \& Larsen-Freeman, 2006) and are synthesized to understand more closely, the facility of English Language Learners' (ELLs') with two languages as they interact in social contexts. The emerging awareness of this collective "social" within a cognitive whole is largely responsible for the increasingly modified view of language learners and for re-envisioning the latter as a "national asset" (Castek et al., 2007).

However, this more expansive and inclusive perspective is not so evident in second language research conducted with certain methodologies. Considered a methodological tool, verbal protocols have been used to investigate the reading processes of language learners (LLs) in a majority of the studies in the second language acquisition (SLA) field. During the inception of this methodology, Aristotle and Plato utilized verbal protocols to invite individuals to provide feedback concerning their thoughts (Pritchard, 1990). Thousands of years later, John Watson (1920) recognized the connection between thinking and the neural activity of "inner speech", which led to the proposition of "thinking aloud"/verbal protocols as a substitute for introspection.

In subsequent decades, Ericsson and Simon $(1984 ; 1993)$ produced a seminal piece based on studies in which researchers utilized concurrent verbal protocols to elicit information concerning participants' thoughts during prescribed tasks. More recently, verbal protocols have gained increased prominence as a tool for understanding reading processes. Yet, Afflerbach (1990) is careful to point out that protocols are themselves flexible methodological tools. He argues for a more socially driven approach, advocating for researchers' awareness of their participants' construction of knowledge during protocols. Yet, when deployed in second language (L2) reading research, the verbal protocol methodology continues to be predominantly driven by cognitivist perspectives (Goo, 2010; Leow, 1997; Leow, Hseih, \& Moreno, 2008; Rao, Gu, Zhang \& Hu, 2007; Zhang, Gu \& Hu, 2007) in which situational determinants (Jenkins, 1979) and constructively responsive elements involved in reading (Pressley \& Afflerbach, 1995) assume little significance.

Considering this, we assert the need for a paradigm shift in the use and interpretation of verbal protocols, generally, and specifically within SLA reading research. As change is experienced in conception of verbal protocols, the shift away from an exclusively cognitive orientation of this methodology creates the need for its conceptualization as a tool, which not only examines cognitive processes but also considers "the social". It is this underlying assumption, which must first be present as a tenet for discussing veridicality of verbal protocols, albeit, if this discussion continues to be a necessity after all is said and done. Notwithstanding, we acknowledge the groundbreaking contribution of Ericsson and Simon's $(1984 ; 1993)$ information processing model, from which many researchers in the SLA field have derived 
guidelines for the procedures of obtaining verbal reports. We therefore utilize the propositions made by Ericsson and Simon $(1984 ; 1993)$ in their seminal review based on verbal protocols as a basis for out interrogation of the literature. While the Ericsson and Simon propositions are solely cognitive in origin, their use here is consistent with the studies that are reviewed as well as the underlying theoretical perspectives of those studies.

\section{VERBAL PROTOCOLS}

Referred to as 'verbal reports' or 'think-alouds' (Bowles \& Leow, 2005; Leow \& Morgan-Short, 2004; Rosa \& O’Neill, 1999), verbal protocols constitute a methodological procedure through which participants report their thought processes while completing a task. Verbal protocols may either be concurrent, retrospective, or introspective (Pressley \& Afflerbach, 1995).

In spite of efforts to validate verbal protocols as a methodological tool, protocol elicitations continue to be criticized with regards to reactivity (Ellis, 2001; Jourdenais, 2001; Leow, 2002). However, in this paper we are not concerned with reactivity per se, but rather with one of its effects. That effect is veridicality, or the probability that "processes underlying behavior may be unconscious and thus not accessible for verbal reporting" as well as the "possibility that verbalizations, when present, may not be closely related to underlying thought processes" (Ericsson \& Simon, 1984; 1993, p. 109). Although identified by Ericsson and Simon $(1984 ; 1993)$ as a key issue in reported protocol data, alerts to monitoring for veridicality appear to have had little consequence in empirical studies based on the extent to which verbal protocols continue to be utilized in various domains (Green, 1998; Ericsson, 1988; Pressley \& Afflerbach, 1995; Hughes \& Parkes, 2003). Yet, the concerns with veridicality seem sufficiently valid to warrant intermittent reviews of protocol analysis (Ericsson, 2006), and by extension, their use with language learners.

\section{THE LITERATURE}

In undertaking the task of examining veridicality, we drew from current research concerning the use of verbal protocols as a methodological tool for LLs (Author \& Kim, 2012). During the preliminary research which provided a description of the state of the research in this area, we examined refereed empirical studies from the SLA field published between the years 2000-2011. These studies involved participants as subjects at every level of the education system, within and outside of the United States, and extended beyond second language research to multilingual inclusive of reading research studies. Overall, 30 empirical studies were selected for the preliminary review (Author \& Kim, 2012). These studies were then categorized based on methodology, i.e., quantitative, qualitative or mixed-methods. Of the 30 empirical studies gathered, 20 were qualitative and mixed-method studies. Given our interest in considering the methodological concerns of verbal protocols within research studies, in which qualitative approaches played a major role, we chose the qualitative and mixed methods studies (which included qualitative research paradigms) for this analysis. Our rationale for the selection of qualitative studies was based on a recent review of the research which noted the tendency of researchers to focus on quantitative studies within the SLA field, specifically with regards to introspection (Richards, 2009). Maintaining an emphasis on qualitative studies in this review would illuminate understanding of the processes engaged in when using verbal protocols from a qualitative research perspective.

\section{FRAMEWORK FOR THE REVIEW: METHOdOLOGICAL RECOMMENDATIONS}

Our framework for analysis was based on Ericsson and Simon's (1993) proposition for the use of verbal protocols. Within this framework, we chose to focus on non-veridicality, i.e., the probability that "processes underlying behavior may be unconscious and thus not accessible for verbal reporting" and "possibility that verbalizations, when present, may not be closely related to underlying thought processes" (Ericsson \& Simon, 1984; 1993, p. 109). To accomplish this goal, we found it necessary to first identify the recommendations related to non-veridicality of verbal protocols as specified by Ericsson and Simon (1984; 1993). The following recommendations appear to be particularly applicable to obtaining veridicality in the use of verbal protocols:

(a) think-aloud data should reflect exactly what is being thought about through the use of concurrent protocols as well as verbal cognitions rather than nonverbal cognitions (images), (concurrent protocols increase representativeness of thoughts).

(b) fully automatic processes are difficult to self-report so it is necessary to slow down processing for such processes or use retrospective reports by having subjects specify their thoughts in response to a specific type of signal which interrupts the automatic process, (slow down processing);

(c) certain types of information will more likely be reflected in protocols than other types of information (i.e., information concerning the product of one's processing may more likely be reflected in the self-report than thoughts that are present as a result or as an inherent part of the thinking process) (emphasize process over product);

(d) asking subjects to provide a generalized description of their processing across trials is particularly problematic because it is possible that only the operations involved in early trials were conscious (tap current processing);

(e) the directions given to participants producing verbal protocols and the testing situation should be such as to discourage participants from providing descriptions or explanations of their processing since reports of intermediate and final products of processing are preferred above descriptions of explanations of processing directions to think-aloud 
(provide verbal protocols) can be rather open ended, or they can direct participants to report a specific type of information that they have in working memory (direct participants to provide non-explanations);

(f) there are individual differences in ability to provide think-aloud reports; it is possible that general verbal ability provides individuals with an advantage to report verbal protocols (consider participants' verbal abilities);

$(\mathrm{g})$ it is critical for the researcher to be able to predict what participants will self-report as they attempt a task (predict study participants' self-reports). (as cited in Pressley \& Afflerbach, 1995, pp. 9-13. The italicized restatement is our elaboration.)

As a framework for investigation, we use these methodological recommendations and considerations to examine veridicality of verbal protocols within the 20 empirical studies reviewed. We acknowledge Ericsson's (2006) caution against lumping all forms of protocol analysis together in seeking a resolution to the challenges faced. We therefore specify the type of protocol being concentrated on as we proceed with analysis.

\section{Selected Studies’'AdHerence to Methodological ReCOMmendations}

\section{A. Increase Representativeness of Thought through Concurrent Protocols}

Ericsson and Simon's (1993) first recommendation suggests the use of concurrent protocols and reports based on verbal cognitions in order to increase the possibility of deriving protocols that reflect exactly the thought process of study participants. As indicated earlier, concurrent methods involve participants' verbalization of thought processes during their engagement with an activity. In these studies utilizing concurrent protocols, reading tasks functioned as the aforementioned activity. All 20 of the research studies referenced employed a certain measure of concurrent protocol methodology, with nine studies utilizing solely concurrent methods (Akyel \& Ercetin, 2009; Alsheikh, 2011; DaalenKapteijns, Elshout-Mohr \& de Glopper, 2001; Dressler, Carlo, Snow, August \& White, 2011; Gascoigne, 2002; Geladari, Griva, \& Mastrothanasis, 2010; Stevenson, Schoonen \& de Glopper, 2007; Zhang, Gu \& Hu, 2007).

For instance, in Alsheikh's (2011) investigation into the strategies used by multilingual students while they read across three languages, participants thought-aloud while reading three passages in the different target languages. Likewise, Daalen-Kapteijns, Elshout-Mohr and de Glopper (2001) examined vocabulary-knowledge-oriented activities of young students through the collection of think-alouds, as participants derived meaning for unknown words from a given context. In yet another instance, Stevenson, Schoonen, and de Glopper (2007) had 253 13-14 year old EFL students indirectly explain their thoughts, that is, provide meta-commentary on what they were thinking. In this instance, the students also concurrently reported their use of language-oriented strategies/content-oriented (based on orientation of processing), regulatory/cognitive/cognitive-iterative strategies (based on type of processing), and aboveclause/clause/below-clause (based on domain of processing) strategies in Dutch and EFL.

The three areas of strategy use in Stevenson, Schoonen, and de Glopper's (2007) study were characterized by distinct, but nuanced, differences. Content-oriented strategies in this case involved an attempt to compensate for absence of linguistic knowledge or processing ability in the participants' attempts to understand the linguistic code of the text. Further, the content-oriented strategies focused on the participant's use of methods to create mental models of the text. The mental models were observed to integrate important text-based propositions with participants' prior knowledge. Participants' regulatory strategies, revealed in their protocol data, were comprised of reflective processes in reading text (e.g., planning, evaluating). Their other cognitive strategies included direct processing which involved mental operations (e.g., translating, paraphrasing) and cognitive-iterative strategies involved reprocessing of text without changing fundamental surface structure of the text (e.g., rereading). Above-clause level, clause level and below-clause level strategies were based on readers' attempts to understand reasonably large chunks of text (e.g., whole paragraphs), whole clauses or smaller parts of text (e.g. morphemes/words/phrases) respectively. Clearly, this elaboration of Stevenson et al (2007) reveals the constitutive nature of individual's social and cognitive strategies deployed while generating a protocol, as well as the use of concurrent methods.

The use of exclusively concurrent methods in these nine studies is significant because it reflects researchers' adherence to Ericsson and Simon's $(1984 ; 1993)$ first consideration: "think-aloud data should reflect exactly what is being thought about through the use of concurrent protocols as well as verbal cognitions rather than nonverbal cognitions (images)" (p. 9).

In contrast to studies that utilized only concurrent methods, five studies obtained retrospective protocols in conjunction with concurrent protocols (Bengeleil \& Paribakht, 2004; Nassaji, 2003; Upton \& Lee-Thompson, 2001; Wesche \& Paribakht, 2000; Yang, 2006). Among these was Upton and Lee-Thompson's (2001) investigation of university-level L2 readers' use of their L1 to aid in understanding of L2 general expository text. The study design had participants think aloud while they read transcripts of their own protocols that had been recorded previously. After they read the transcripts of their protocols, the participants were asked to make comments about their reading processes in order to explain what they had done while they were reading. The validity of such a data generation and collection process is in part supported by the method of stimulated recall (Gass \& Mackey, 2000), wherein participants are confronted with data that they have previously created and asked to respond to it in some way. However, the issue in the current review is the degree to which this stimulated data is related to the thought processes of the participants when they were engaged in the proscribed experimental task. According to guidelines, the stimulated recall would have less to do with traces of processing than would the concurrent data. 
In Weshe and Paribakth's (2000) exploration of ten intermediate-level ESL students' responses to different words learning tasks, participants were required to (a) read a list of target words, and locate these underlined words in the text, identify which target words were "connectives" and then find and circle them in the text, (p. 201), (b) match a given list of target words with a longer list of definitions to ensure that they could recognize the target words and their meanings, (pp. 201-202), (c) use a derivational grid on which target words were located to fill in derivations that had been omitted, (d) read given text and identify underlined words which corresponded to the definitions provided, (e) replace underlined words as presented in novel sentences with similar underlined words from the text (p. 203), (f) identify discourse functions of target connectives as these were used in the reading text and $(\mathrm{g})$ rearrange strings of words in which target words were included into sentences in order to direct learners' attention to the characteristics of target words as required in producing new sentences (p. 204). In this research study, the researchers employed both immediate and delayed retrospection, along with concurrent protocols. For the retrospective protocols, the researchers had participants engage in reflection on how they had performed each task, both at the end of the each exercise as well as at the end of the research session. In fact, both of the reflective responses, at the end of each exercise and at the end of the research session are after the fact, and decidedly different from the concurrent protocols. Characteristically, comparisons between concurrent and retrospective data are not undertaken with any of these studies. It is also likely that with such an elaborate task array, participants' attention would distributed and less likely to be focused on concurrent processing.

The preceding five studies, (Bengeleil \& Paribakht, 2004; Nassaji, 2003; Upton \& Lee-Thompson, 2001; Wesche \& Paribakht, 2000; Yang, 2006) utilized retrospective protocols in contrast with Ericsson and Simon's (1984; 1993) recommendations for concurrent use as a means of increasing representativeness of verbal protocols. Therefore, the results of these studies may constitute a certain measure of unrepresentativeness. Since the concurrent protocols in the studies referenced were obtained prior to reflection/retrospection, there was likely little interference. However, any descriptive reflection before the concurrent protocol would produce interference and therefore be less representative of actual process. Additionally, the value of the reflection as representative becomes a prominent issue in this context because (a) the question arises as to whether reflection remains aligned with the reading process and (b) the value of the reflection becomes dependent on the participants' capacity to remember the actual processes engaged in during protocol collection. Of course, these methodological questions must be viewed in terms of what claims and uses the researchers make with retrospective data.

Related to the issue of representativeness, two studies utilized introspection to accompany concurrent protocols (Chun, 2001; Lee-Thompson, 2008). For example, Lee-Thompson (2008) explored 8 Chinese students in their third year of learning English. The study focused on the students' uses of reading strategies when processing two Chinese texts (narrative and argumentative). Researchers first asked participants to think aloud when they came to break points marked by red dots at the end of each paragraph, and conducted introspection when they asked participants to respond to prompts by providing explanations about their thoughts. In the case of Chun's (2001) participants, the researchers tracked German EFL university students' behavior with ActionCatcher software as they read two texts online while using an internal glossary and dictionaries. As they completed the accompanying exercises related to the reading of each text, they were required to explain each action, i.e., what went on through their minds and to comment on the usefulness of the program. Because these participants were required to simultaneously report their concurrent thoughts and then immediately comment upon those thoughts, the discrete nature of either of the data sets would be difficult to determine.

In both the Lee \& and Thompson, as well as Chun studies, the indirect explanation of thoughts differed significantly from providing a concurrent statement of thought. Asking participants to recall the thought processes involved in the generation of a previous protocol is calling for introspective accounts regarding this protocol. When this is done after the completed protocol, one would anticipate little interference in the actual protocol output. However, the content generated during the introspection would subject protocols to the same limitations as other forms of introspection, and raise the concern that introspection was unrelated to the content of the protocol.

Overall, the guideline for representativeness through concurrent protocol use was generally found to be incorporated into many of the studies, even in the presence of other verbal report methodologies (i.e., introspection, retrospection). Specifically, in the context of concurrency, even when retrospection and introspection were deployed, participants were invited to state their thought processes as they read, indicating that the reports were more likely based on verbal cognitions as opposed to non-verbal cognitions. It is therefore safe to say that in the first nine studies referenced which relied solely on concurrent reports (e.g., Akyel \& Ercetin, 2009; Alsheikh, 2011; Daalen-Kapteijns, Elshout-Mohr \& de Glopper, 2001; Dressler, Carlo, Snow, August \& White, 20119; Gascoigne, 2002; Geladari, Griva, \& Mastrothanasis, 2010; Stevenson, Schoonen \& de Glopper, 2007; Zhang, Gu \& Hu, 2007), there was a greater likelihood that a "subset of the information actually heeded in short-term memory" was reflected in the protocols (Pressley \& Afflerbach, 1995, p. 9). This is consistent with Ericsson and Simon's $(1984 ; 1993)$ recommendation for use of concurrent verbal protocols and therefore, veridicality of the protocol outputs should not have been affected in these studies. However, in the subsequent studies examined previously (Bengeleil \& Paribakht, 2004; Lee-Thomspon, 2008; Nassaji, 2003; Upton \& Lee-Thompson, 2001; Wesche \& Paribakht, 2000; Yang, 2006), in spite of concurrent protocols being incorporated into research, the presence of retrospection and introspection may have increased the possibility of unrepresentativeness of the combined data obtained. Again, it depends upon how the researchers' used the retrospective data in their studies. 


\section{B. Slow Down Processing}

In their second recommendation, Ericsson and Simon (1993) highlight the importance of slowing down automatized processes, specifically by prompting for verbal protocols in order to sufficiently interrupt otherwise automatized processes. One of the empirical studies reviewed manifested evidence of the researcher' attempt to slow down the reading process in keeping with this recommendation (Lee-Thompson, 2008). In Lee-Thompson's (2008) approach, break points in the form of red dots at the end of each paragraph functioned as prompts to the study participant as the protocol was obtained. The fact that the reading process was interrupted at the conclusion of the paragraph, and not sentence or word level, is significant as one may argue about the effectiveness of such a method in slowing down the reading process, without disrupting processing within sentences or clauses.

At the end of a paragraph, a researcher would be more likely to tap comprehension as a completed product and less likely to intercept comprehension as a process. Since protocols intend to tap process information, waiting until the end of the paragraph has serious implications for representativeness of the data. While the task (reading) is in fact slowed, it is not until the process is likely completed. Interrupting the reading process at the end of a paragraph would be less likely to create a problem with comprehension for readers but more likely to be related to the content of processing. Consequently, researchers' verbal prompts such as random "tell me what you're thinking" interspersed inter- and/or intra-sententially are likely to interrupt the processing of the immediate clause. Conversely, embedded red dots at the sentential (and less frequently) intra-sentential clause boundaries would not interrupt syntactic processing (Fodor, Garrett \& Bever, 1968; Bresnan, 1978). This is due to the fact that evidence from the literature on semantic processing shows that such processing required of comprehension happens more interstitially at clause boundaries (Jackendoff, 1978). Nevertheless, it remains clear that end-of-paragraph prompting would not interfere with process.

Lee-Thompson (2008) not only used red dots as a signal for interruption of the reading process, but also prompted participants to state what they were thinking while they read. Notably, this practice of prompting was more of an exception than the rule. The absence of prompting during the collection of concurrent reports is problematic as Ericsson and Simon $(1984 ; 1993)$ acknowledge that fully automatic processes such as reading are difficult to self-report. They therefore recommend the use of concurrent protocols, which do interrupt with prompting, to facilitate this process. However, Ericsson and Simon $(1984 ; 1993)$ also support the use of retrospective protocols by having subjects specify their thoughts in response to the specific signal which had previously interrupted the automatic process (i.e., reading) in which participants were engaged. They further assert that participants be discouraged from providing descriptions or explanations of their processing (see Ericsson and Simon, 1984; 1993, p. 109). However, one might argue that the recommendation for the use of retrospective reports clearly contradicts Ericsson and Simon's (1983; 1994) recommendation for the use of concurrent reports which ensure that thought processes are closely related to verbalizations. Perhaps, Ericsson and Simon's (1984; 1993) contradiction here is the result of the use of numerous studies unrelated to reading in their seminal review.

But Ericsson and Simon's $(1984 ; 1993)$ review did draw upon research that involved approaches directed at understanding skilled reading, and specific instances are present in which SLA/LL researchers may benefit from specific guidelines for eliciting reports concerning the reading process (p. 254). Among the guidelines pertaining to reading as an automated process, Ericsson and Simon (1993) assert that "comprehension information must be accessed in LTM to generate coherent representation of a text's meaning" (Ericsson \& Simon, 1984; 1993, p. 254). In fact, the authors cited researchers who "slowed down" the reading process to permit more complete verbalizations by displaying sentences separately with several lines or some elapsed time between the presentation of sentences, i.e., showing participants one sentence at a time and using retrospective reports after reading. They note that while the nature of verbalization remained the same, in each case, there was a remarkable increase in the amount of verbalization obtained when prompted retrospective accounts were elicited.

Pressley and Afflerbach (1995) allude to both the slowing down of processing and representativeness in their exploration of verbal protocol research in relation to reading processes. SLA researchers' recognition of the importance of slowing down the automated process of reading, as well as their intent to preserve comprehension through the use of complementary protocol formats, may therefore very well be the basis for five of the research studies which deploy retrospective protocols in conjunction with other forms of verbal reports (Upton \& Lee-Thompson, 2001; Wesche \& Paribakht, 2000). What is apparent is that when researchers did choose to deploy concurrent protocols, thus disrupting ongoing reading processes, these researchers also included retrospective protocols, perhaps as a "remedy" for fractured comprehension.

Ericsson (2003) validates the retrospective tool in situations where study participants are merely asked to recall their thoughts, but warns against retrospection in which participants are required to describe "cognitive activities that go beyond immediate recall sequences of already generated thoughts" (p. 14). Ericsson's cautions may be partially responsible for researchers' reluctance to abandon concurrent reporting in favor of retrospective reports.

In keeping with Ericsson's (2003) recommendation, three of the studies that were reviewed involved the use of immediate retrospection (Nassaji, 2003; Upton \& Lee-Thompson, 2001; Wesche \& Paribakht, 2000). Nassaji's (2003) consideration of 21 adult ESL learners' inference of word meanings from context in a text first utilized concurrent reports to have participants report what came to mind as they inferred meanings of words. Subsequently, Nassaji (2003) used immediate retrospective protocols to find out whether learners had additional comments on their familiarity with 
the words and/or concerning their inference processes regarding the meanings of the words. Similarly, Upton and LeeThompson (2001) collected both concurrent protocols and immediate, retrospective protocols as they examined how 20 native speakers of Chinese and Japanese used their L1 as an aid to understanding English general, expository text. In neither of the studies was retrospection employed independently. This is potentially productive research practice as independent retrospection is not likely to tap processes.

Ericsson and Simon's $(1984 ; 1993)$ recommendation that researchers take pains to "slow down" the reading processing of their participants could have been the basis for researchers' choice to utilize retrospective acts of processing in conjunction with concurrent protocols. The use of concurrent protocols would indeed slow down participants' processing and the addition of the retrospective account would provide needed detail to the quickly collected concurrent data.

\section{Emphasize Process over Product}

Ericsson and Simon's (1984; 1993) third recommendation and caution regarding verbal protocols indicates the potential for products of processing taking preeminence over participants' awareness of their process data. Of the 20 studies considered, nine were product-oriented (Abbott, 2006; Bengeleil \& Paribakht, 2004; Chun, 2001; DaalenKapteijns, Elshout-Mohr \& de Glopper, 2001; Dressler, Carlo, Snow, August \& White, 2009; Gascoigne, 2002; Nassaji, 2003; Paribakht, 2005; Lee-Thompson, 2008). These studies involved products/tasks that were inclusive of drawing inferences, answering questions, and retelling. For instance, in Gascoigne's (2002) evaluation of 16 Native English speaking students' recall of idea units based on bottom-up and top-down processes of reading, students read for the purpose of writing down everything they could recall. In this study, participants vocalized thoughts about the text or thoughts occurring during the product-oriented task.

On the other hand, Paribakht's (2005) 20 Farsi-speaking undergraduate students were first required to read English text quickly for general comprehension, and then asked to repeat the reading in order to guess meanings of unfamiliar boldfaced target words in text (p. 711). While the students completed these process-oriented tasks, they verbalized their thoughts using the preferred language: English, Farsi, or both languages. In this case, the explicit direction for the vocabulary task required the readers to focus on products (the vocabulary) rather than the processes of their thinking during reading. In both of these preceding studies, the focus on product likely influences the verbal protocols that were collected.

More consistent with Ericsson and Simon's (1984; 1993) caution regarding product over process, seven studies were process-oriented (Alsheikh 2011; Geladari et al., 2010; Stevenson, Schoonen \& de Glopper, 2007; Upton \& LeeThompson, 2001; Wesche \& Paribakht, 2000; Yang, 2006; Zhang, Gu \& Hu, 2007). For example, Geladari et al.'s (2010) investigation of reading difficulties, as well as cognitive and metacognitive strategies deployed by bilingual students while reading, was not geared towards students producing a result. Rather, Geladari et al (2010) focused on how study participants understood the meanings of words and employed reading strategies for their understanding of text.

Similarly, Yang (2006) and Zhang, Gu and $\mathrm{Hu}$ (2007) emphasized the reading strategies of study participants. In Yang's (2006) study, 20 intermediate level EFL students in Taiwan were required to read English texts explaining motion, then independently generate meanings emanating from the text in either English or Mandarin Chinese, as preferred. Researchers collected both concurrent reports, in which participants reported their thoughts, and retrospective reports, in which participants explained how they comprehended the sentences, as well as the strategies they used to deal with challenges in comprehension. Focusing on ESL learners, Zhang, Gu and Hu's (2007) research study was comprised of 18 Singaporean Grades 4-6, high- and low-proficiency learners of English. Each participant was required to read 6 English narrative and 6 English expository texts of varied difficulty levels and to verbalize concurrently what they were thinking while they read. In this study, the goal of the researchers was to identify reading strategies that successful Singaporean learners of English use and to note differences in strategy use across grade levels and based on varied levels of reading difficulty. As such, participants were not expected to complete a task as a result of reading, but the reading of the passages themselves constituted the only task participants were required to perform.

Given that the aforementioned studies (Alsheikh 2011; Geladari et al., 2010; Stevenson, Schoonen \& de Glopper, 2007; Upton \& Lee-Thompson, 2001; Wesche \& Paribakht, 2000; Yang, 2006; Zhang, Gu, \& Hu, 2007) constituted no product to which participants were expected to aspire or achieve, there was a greater probability of preservation of a possible process orientation.

For studies where protocols were influenced by product specification, such as the ones in which study participants anticipated performing an activity (e.g. retelling information, making inferences, answering questions) as an adjunct to the reading task, Ericsson and Simon $(1984 ; 1993)$ noted that there was a greater likelihood that the verbal protocols would reflect the anticipated task rather than be a representation of their awareness of the ongoing reading process. While Ericsson and Simon $(1984 ; 1993)$ do not explicitly state that process-oriented tasks would place a greater onus on the participant to report the process, it may be hypothesized that such would be the case. If the goal of a researcher is to understand reading processes, then research tasks should be geared towards maximizing the probability that the verbal protocols obtained during the reading process would be most representative of that participant's processing, and, therefore, process-oriented studies would more than likely be the norm than would those with product-influenced protocols. 


\section{Tap Current Processing}

Recommendation four holds that participants not be asked to provide a generalized description of their processing across trials because of the possibility that conscious attention would be placed only on operations involved in earlier trials of the verbal reporting process. This would result in the early observations being used as a template or default response, and therefore these would be more readily reported. Of course, such a response set offers little in the way of evidence of processing. Our analysis finds general adherence to this recommendation. Only one of the studies involved participant verbalization across trials (Wesche \& Paribakht, 2000). In this case, 10 intermediate-level ESL students at a Canadian university responded to different word learning tasks and subsequently produced retrospective protocols concerning the tasks at the end of the research session. As such, veridicality would likely be affected since participants would be more inclined to report information concerning the initial word learning tasks encountered in the research process. Fortunately, veridicality of the remaining 19 studies was not affected in this regard.

\section{E. Direct Participants to Provide Non-explanations}

For recommendation five, pertaining the directions provided to study participants, Ericsson and Simon (1984; 1993) maintained:

The directions given to think-aloud subjects and the testing situation should be such as to

discourage participants from providing descriptions or explanations of their processing as

reports of intermediate and final products of processing are preferred above descriptions

of explanations of processing. Directions to think-aloud (provide verbal protocols) can

be rather open ended, or they can direct participants to report a specific type of

information that they have in working memory. (pp. 10-11)

"Descriptions or explanations of their processing," as noted above may more explicitly be referred to as "introspective" protocols. In two of the 20 studies (Chun, 2001; Lee-Thompson, 2008), the researchers employed such introspection. The directions for introspection procedures in these studies required study participants to describe and/or explain their thought processes. For instance, in Chun's (2001) investigation of 23 learners' consultation of internal and external glossaries while reading on the web, students were to explain each action, what was going on through their minds while they worked, and to comment on the usefulness of features of the program they used during the exercise.

Asking for introspective data conflicts with Ericsson and Simon's (1984; 1993) recommendation as well as Ericsson's (2006) confirmation that the "closest connection between actual thoughts and verbal reports is found when people verbalize thoughts that are spontaneously attended to during task completion" (p. 221). The contrast between the requirements of introspection and the recommendation that directions given discourage participants from providing explanations of process therefore contributes to the likelihood that protocol data collected was non-veridical. Ericsson and Simon's $(1984 ; 1993)$ admonition against this directive is predicated upon the fact that asking for a description or explanation imputes additional participant processing, and the residue from that processing is offered along with thinking produced "within the moment" of the task. A substitute for this directive, in Ericsson and Simon's (1984; 1993) opinion, could have possibly been to "tell what you are thinking".

In the three studies referenced above (Chun, 2001; Lee-Thompson, 2008; Wesche \& Paribakht, 2000), participants were directed to describe what they thought while they read and were not required to state specific information about the contents of working memory. Since Ericsson and Simon's $(1984 ; 1993)$ guidelines indicate that directions to thinkaloud (provide verbal protocols) can be rather open ended, or they can direct participants to report a specific type of information that they have in working memory, Ericsson and Simon (1984; 1993) do not necessarily state negative implications for pursuing either direction. What is noteworthy, however, is the recognition that directions impact the nature of reports and therefore, researchers should be willing to acknowledge this impact in presentation of their findings.

\section{F. Consider Participants' Verbal Abilities}

Ericsson and Simon's $(1984 ; 1993)$ sixth recommendation relates to individuals' differences in their abilities to produce think-aloud protocols and the possibility that increased general verbal ability provides individuals with an advantage to report verbal protocols. The importance of considering individual differences of readers and how they vary in their linguistic competence, their background knowledge relative to a target text, and their specific experiences in the interpretations of texts is of paramount importance, not only with regards to their ability to verbalize, but in relation to their background experiences as individual language learners (LLs). As Pressley and Afflerbach (1995) note, study participants vary in their knowledge, experiences and interpretations of texts.

It is therefore problematic that in the studies referenced, researchers generally appear to be oblivious to the nuances between individual participants as they undertake a myriad of reading tasks. For example, in many situations, researchers indicate that participants were Spanish, English, and French students, or state the current level at which these participants operate with reference to a language learned. However, this information hardly accounts for variations in elements such as year of first exposure to the L1, time spent learning the L1, number of countries in which students lived, number of languages spoken in country in which students lived, language predominantly spoken in the home, language in which students were officially taught in school, all of which are variables which significantly affect students' abilities to verbalize thoughts in conjunction with reading tasks. 
Bernhardt (2005) concurs with our observed inattention paid to individual variations among participants in empirical studies involving language learners (LLs). She notes that studies involving LLs tend to involve participants who originate from diverse and multiple language backgrounds, and whose experiences with each of any given languages in a study scarcely bear equal resemblance. As such, she asserts that students' identities are to be factored into the reading processes during research of their experiences, and if a reliable representation of their reading is to be obtained, it may be necessary to capture, as much as possible, an accounting of their varied backgrounds, (i.e., home languages and cultures). Consideration of the impact of such factors on the variability of verbal protocols produced within a given context may be easily dismissible because of the arduous nature of such task. However, the practical difficulties in controlling for linguistic and cultural variability does not negate the integral role of such elements in interpretation of verbal report data.

Interestingly, on this note of individual difference, researchers in the reviewed studies generally failed to provide indications of any measures of verbal ability, but rather appeared to confine their descriptions to statements indicating that study participants were adult learners or learners at the higher levels of the K-12 system. Researchers' tendency to examine reading processes of adult learners at the expense of that of younger participants' using verbal protocols has previously been cited as problematic (see Fitzgerald, 1995). Although most likely predicated upon Ericsson and Simon's $(1984 ; 1993)$ observation that younger learners are less likely to possess the required additional attentional capacity to report their thought processes, researchers should heed Pressley and Afflerbach's (1995) caution that level of educational proficiency does not automatically translate into readers' expertise status, and therefore the assumed, concomitant ability to verbalize may be an unfounded assumption. In other words, it may not be the case that "good" readers are also "good" verbalizers. It is also problematic to operationalize verbosity for selection procedures. The fact that research with LLs continues to be conducted, albeit sparingly, but nonetheless successfully, with students in the younger grades (need a couple of citations here), should account for evidence that verbal protocols do elicit substantive information with adult as well as younger learners. While it may be difficult to determine verbal ability in the initial selection of study participants, research may be geared towards procedures which allow for differentiation of verbal abilities in participants identified for a given empirical study. In this way, interpretation of the protocol data might be allowed to reflect these differentiated abilities.

\section{G. Predict Study Participants' Self-reports}

Ericsson and Simon's $(1984 ; 1993)$ final recommendation focused on researchers' ability to predict study participants' abilities to self-report as they attempted a task. As Ericsson (2003) explains, the completion of a task is dependent upon a predictable set of prior knowledge, which makes it possible for a researcher to anticipate the procedures in which a study participant might engage in to arrive at a particular solution to the task parameters. More appropriately referred to as task analysis, this assessment of the probable sequential elements of a task "provides a set of possible thought sequences for its successful performance, where the application of each alternative procedure is associated with a different sequence of thoughts" (Ericsson, 2003, p. 9). In the research studies considered, while there is reference to the expected responses (strategies, inferences) from study participants (Chun, 2001; Bengeleil and Paribakht, 2004, Lee-Thompson, 2008), there is no study in which a task analysis is provided as an indication of the probable and possible sequences to be expected for alternative procedures in a task or a given series of tasks. While the tasks referenced by Ericsson (2003) for illustration are largely mathematical in nature, it may be possible that a similar procedure can be followed to appropriate a method for determining predictability of verbal protocols of reading, in an effort to enhance veridicality.

\section{Summary}

In the previous discussion, we explored the extent to which studies involving language learners (LLs) adhered to Ericsson and Simon's $(1984 ; 1993)$ recommendations with regards to veridicality of verbal protocols. While researchers tended to adhere to the recommendations related to the use of concurrent protocols, the elicitation of responses concerning current processing and in general, the avoidance of requiring participants to provide verbal explanations, there was evidence to indicate that researchers failed to slow down processing, consider variations in participants' verbal abilities within interpretations of the data and to predict the probable contents of participants" self-reports. This indicates that due consideration has not been given to verbal protocols as utilized within a cognitive framework, and specifically within Ericsson and Simon's $(1984$; 1993) cautionary rubric. Failure to attend to their rubric may result in protocols with embedded erroneous data. Awareness of these errant data have created certain fundamental arguments regarding veridicality, resulting from, but apart from those proposed by Ericsson and Simon (1984; 1993). We now consider these arguments.

\section{FUndAMENTAL ARGUMENTS}

Three fundamental arguments relate to the presence of non-veridicality in verbal protocols of language learners (LLs). In these arguments, the assumption is that veridicality of verbal reports is present when verbal output matches mental operations. As such, when this is not the case, non-veridicality is theorized to stem from two major types of errors involved in the data elicitation process. Russo, Johnson, and Stephens (1989) labeled these: errors of omission and 
errors of commission. We identified a third error type, which we have labeled: the presence of language(s) as an inherent variable.

\section{Language as an Inherent Variable}

Central to our argument concerning the value of verbal reports with second language learners is the "elephant in the room" issue, that is, language itself, was not controlled as a variable, i.e., the studies in Ericsson and Simon's (1984; 1993) seminal review appeared to have largely involved monolingual study participants. In addition, of the 38 studies reviewed by Pressley and Afflerbach (1995), only two studies comprised of second language learners. With LLs, whose linguistic abilities further confound representation of memory processes, depending on verbal reports to access their reading processes raises even further issues of credibility. Ericsson and Simon (1984; 1993) illustrate the complexity involved in the basic process of producing a protocol when they state:

Persons fluent in a second language can usually think aloud in that language even while thinking internally in the oral code of their native language or in non-oral code. In this case, there is nearly a one-to-one mapping between structures in the oral code of the first language and the code of the second language that is used for vocalization. How much the thinking is slowed down will then be a function of the subject's skill in the second language. (p. 250)

Whereas certain studies in second language learning do allow such learners to verbalize processes in the language with which they are most familiar, the challenges inherent in reading and performing a task in a second language (e.g., usually English), subsequently conducting interpretation through the native language, and deciding whether to revert back to English or to relay the contents of memory in the native language are significant and do influence the composition of protocols.

Yet another linguistically-based concern arises from Russo, Johnson and Stephens, (1989). They raise concerns regarding the entire enterprise of collecting protocols, and suggest that judgments and decisions concerning veridicality in the use of verbalized protocols are misplaced. These beliefs in the futility of testing the veridicality of a verbal report are potent when its accuracy, relative to the underlying processes, is already significantly altered by verbalization of the process. The immediate response that comes to mind is "Why bother?" And our answer is that protocols continue to be used. Russo, et al.'s concern has been largely dismissed in studies with monolingual learners because of the English language existing across groups and across studies. That is not to suggest that these issues are no longer operating, but that research attention has shifted in focus, away from this problem of representation. It remains a crucial point for L1 and L2 research, particularly considering L2 research often is influenced by research undertaken in single language studies. In L2/SLA/LL research, language is an added, inherent variable, which dictates the linguistic product of such learners, and therefore any attempt to verbalize reports not only undergoes transformation during verbalization, but also experiences alteration due to linguistic interference. In other words, the language task required and the demand to verbalize that task find themselves competing for the linguistic capacity (Sanz, Lin, Lado, Bowden \& Stafford, 2009), thereby affecting completeness (omission) and accuracy (commission) of the verbal protocols.

Consistent with these claims, contemporary theoretical trends seem to justify the illogicality of attempting to validate verbal protocols. Smagorinksy's sociocultural view of verbal protocols asserts that speech is socially constructed and therefore not a reflection of cognitive processes. Therefore, there is less focus on whether contents of the mind "spill over" in contents of talk (Smagorinsky, 2011). His attempt at reconceptualizing verbal protocols draws from both Ericsson and Simon's (1995) information processing (i.e., cognitivist) and Vygotsky's socio-cultural-historical theory. In this regard, Smagorinsky (2011) presents verbal protocols as a methodological tool that elicits 'talk about thinking', and therefore may be altered in literacy research to elucidate understanding of the social nature of speech (Smagorinsky, 2011). Drawing upon Cole's (1996) view of the interrelatedness between cultural and biological development, and Bakhtin's (1986) addressitivity and dialogicality, Smagorinsky (2011) maintains that "egocentric speech and thinkaloud methodologies are both part of a hidden dialogue" (p. 237) and that the researcher's concern in obtaining a verbal protocol, should be to explore the intersubjectivity between the researcher and participant in the participant's construction of the verbal report within a particular reading context and task. This presupposes that veridicality regarding protocols be placed on a backburner since nuanced understandings of difference in a verbal protocol become an expected component of the research process and even central to investigation. However, it is important to note that this argument is directed towards literacy research in the monolingual context and therefore does not consider crosslinguistic features (Herdina \& Jessner, 2002; Jessner, 2008) present in LLs' reading processes. Yet, Smagorinsky (2011) does provide an alternative perspective on the use of verbal protocols with LL participants, that one would not only expect the types of differences detailed in this critique, but also treat them as informative differences from monolingual participants.

\section{A WAY FORWARD}

In the preceding argument, we first utilized a cognitivist approach to interrogate 20 LL reading research studies involving the use of verbal protocols on the basis of Ericsson and Simon's (1984; 1993) recommendations. In this process, it was observed that researchers aligned with a few of the guidelines for obtaining veridical protocols, but failed to adhere to others. This suggests that from a cognitivist's perspective, we are justified in being concerned regarding the veridicality of verbal reports. We then discussed veridicality of LLs' verbal protocols based on the possibility that errors of omission, errors of commission and the role language as an inherent variable operated to 
invalidate these reports. We concluded with consideration of the arguments against veridicality based on groundbreaking theoretical trends which signify the importance of a holistic approach to literacy research as opposed to the dichotomized cognitive versus sociocultural notion. While Smagorinsky's (2011) work is yet to be extended to LLs, we concur that it does interrupt debates grounded solely in cognitivist notions of verbal protocols, and although a sociocultural approach to exploring critical issues within verbal protocols does not negate the critical nature of LLs' cognitive capacities in the reading process (Bowles, 2010a; Bowles, 2010b; Bowles \& Leow, 2005), it does alter the nature of the arguments raised with regards to this methodology.

Currently, as has been illustrated, the veridicality of verbal protocols as used with monolinguals is disputable enough to devalue claims for its use in second language research. This finding is credible from a solely cognitive perspective on verbal protocols. Not only is there a heightened possibility of errors of omission with LLs, but there is also the tendency for errors of commission to be exacerbated. But this argument, made from a cognitive perspective, is transformed by adopting a socio-cultural perspective. Explanations and understandings of verbal protocols within L2/SLA/LL contexts should integrate elements from both cognitive and socio-cultural theories. Mindful integration of cognitive and sociocultural thinking can shift the focus from accuracy of verbal protocols to the nuances inherent in linguistic and cultural differences demonstrated in LLs' reading processes, as revealed in protocol accounts.

Rather than emphasize the need for greater attention to Ericsson and Simon's $(1984 ; 1993)$ recommendations, in failed attempts to maintain rigor and veridicality of such LLs' protocols, an alternative approach is to systematically explore via empirical studies the ways in which LL's reading processes constitute social, linguistic, and cultural artifacts as they construct meaning in the context of literacy within the $21^{\text {st }}$ century. As such, the previous call for more systematic research into the validity of verbal protocols for language learners (Bowles, 2008; Fitzgerald, 1995; Leow \& Morgan-Short; 2004; Pressley \& Afflerbach, 1995) may now be replaced by the necessity to delve into verbal protocols as a sociocultural tool for better understanding the reading processes of LLs.

\section{ACKNOWLEDGMENT}

We would like to thank Dr. Deoksoon Kim for her helpful comments and feedback during the completion of this project.

\section{REFERENCES}

[1] Abbott, M. (2006). ESL reading strategies: Differences in Arabic and Mandarin speaker test performance. Language Learning $56.4,633-670$.

[2] Afflerbach, P. (1990). The influence of prior knowledge and text genre on readers' prediction strategies. Journal of Reading Behavior 22, 131-148.

[3] Akyel, A., \& G. Erçetin (2009). Hypermedia reading strategies employed by advanced learners of English. System 37.1, 136152.

[4] Alsheikh, N.O. (2011). Three readers, three languages, three texts: The strategic reading of multilingual and multiliterate readers. The Reading Matrix 11.1, 34-53.

[5] Author \& D. Kim. (2012). Verbal reports in LLs' reading processes. Unpublished manuscript.

[6] Bakhtin, M. M. (1986). Speech genres and other late essays. Austin: University of Texas Press.

[7] Bengeleil, N.F. \& T.S. Paribakht. (2004). L2 reading proficiency and lexical inferencing by university EFL learners. The Canadian Modern Language Review 61.2, 225-249.

[8] Bernhardt, E. (2005). Progress and procrastination in second language reading. Annual Review of Applied Linguistics 25, 133150 .

[9] Bowles, M. A. (2008). Task type and reactivity of verbal reports in SLA: A first look at a L2 task other than reading. Studies in Second Language Acquisition 30.3, 359-387.

[10] Bowles, M.A. (2010a). Concurrent verbal reports in second language acquisition research. Annual Review of Applied Linguistics 30, 111-127.

[11] Bowles, M. A. (2010b). The think-aloud controversy in second language research. New York: Routledge.

[12] Bowles, M. A., \& R. P. Leow. (2005). Reactivity and type of verbal report in SLA research methodology: Expanding the scope of investigation. Studies in Second Language Acquisition 27.3, 415-440.

[13] Bresnan, J. (1978). A realistic transformational grammar. In M. Halle, J. Bresnan \& G. Miller (eds.), Linguistic theory and psychological reality. Cambridge, MA: MIT Press, 1-59.

[14] Castek, J. et al. (2007). Developing new literacies among multilingual learners in the elementary grades. In L. Parker (ed.), Technology-mediated learning environments for young English learners: Connections in and out of school. Mahwah, NJ: Lawrence Erlbaum Associates, 111-153.

[15] Cole, M. (1996). Cultural psychology: A once and future discipline. Cambridge, MA: Harvard University Press.

[16] Chun, D.M. (2001). L2 reading on the web: Strategies for accessing information in hypermedia. Computer Assisted Language Learning 14.5, 367-403.

[17] Daalen-Kapteijns, M., M. Elshout-Mohr \& K. de Glopper. (2001). Deriving the meaning of unknown words from multiple contexts. Language Learning 51.1, 145-181.

[18] Dressler, C., M. S. Carlo, C. E. Snow, D. August \& C.E. White. (2011). Spanish-speaking students' use of cognate knowledge to infer the meaning of English words. Bilingualism: Language and Cognition 14.2, 243-255.

[19] Ellis, R. (2001). Investigating form-focused instruction. Language Learning 51, 1-46. 
[20] Ellis, N. \& D. Larsen-Freeman (2006). Language emergence: Implications for applied linguistics-Introduction to the special issue. Applied Linguistics 27, 558-589.

[21] Ericsson, K. A. (1988). Concurrent verbal reports on reading and text comprehension. Text 8, 295-325.

[22] Ericsson, K. A. (2003). Valid and non-reactive verbalization of thoughts during performance of tasks: Towards a solution of the central problems of introspection as a source of scientific data. Journal of Consciousness Studies 10.9-10, 1-18.

[23] Ericsson, K. A. (2006). Protocol analysis and expert thought: Concurrent verbalizations of thinking during experts' performance on representative task. In K. A. Ericsson, N. Charness, P. Feltovich, and R. R. Hoffman (eds.), Cambridge handbook of expertise and expert performance. Cambridge, UK: Cambridge University Press, 223-242.

[24] Ericsson, K. A., \& H. A. Simon. (1984/1993). Protocol analysis: Verbal reports as data. Cambridge, MA: MIT Press. (Original work published 1984).

[25] Fitzgerald, J. (1995). English-as-a-second-language learners' cognitive reading processes: A review of research in the United States. Review of Educational Research 65.2, 145-190.

[26] Fodor, J., M. Garrett, \& T. Bever. (1968). Some syntactic determinants of sentential complexity, II: Verb structure. Perception and Psychophysics 3, 453-461.

[27] Gascoigne, C. (2002). Documenting the initial second language reading experience: The readers speak. Foreign Language Annals 35.5, 554-560.

[28] Gass, S. \& A. Mackey. (2000). Stimulated recall methodology in second language research. Mahwah, NJ: Erlbaum.

[29] Geladari, A., E. Griva \& K. Mastrothanasis. (2010). A record of bilingual elementary students' reading strategies in Greek as a second language. Procedia-Social and Behavioral Sciences 2.2, 3764-3769.

[30] Goo, J. (2010). Working memory and reactivity. Language Learning 60.4, 712-752.

[31] Grabe, W. (2009). Reading in a second language: Moving from theory to practice. New York, NY: Cambridge University Press

[32] Green, A. J. F. (1998). Using verbal protocols in language testing research: A handbook. Cambridge, UK: Cambridge University Press.

[33] Herdina, P. \& U. Jessner. (2002). A dynamic model of multilingualism: Perspectives of change in psycholinguistics. Clevedon, UK: Multilingual Matters Ltd.

[34] Hughes, J. \& S. Parkes. (2003). Trends in the use of verbal protocol analysis in software engineering research. Behavior \& Information Technology 22, 127-140.

[35] Jackendoff, R. (1978). Grammar as evidence for conceptual structure. In M. Halle, J. Bresnan, \& G. Miller (Ed.). Linguistic theory and psychological reality. Cambridge, MA: MIT Press, 201-228.

[36] Jenkins, J. J. (1979). Four parts to remember: A tetrahedral model of memory experiments. In L. A. Cermak \& F. I. M. Craik (eds.), Levels of processing in human memory. Hillsdale, NJ: Lawrence Erlbaum Associates, 429-446.

[37] Jessner, U. (2008). Multicompetence approaches to language proficiency development in multilingual education. In J. Cummins \& N. H. Hornberger. (Eds.), Encyclopedia of language and education (2 $2^{\text {nd }}$ edn.). New York: Springer, 91-201.

[38] Jourdenais, R. (2001). Protocol analysis and SLA. In P. Robinson (Ed.), Cognition and second language acquisition. New York: Cambridge University Press, 354-375.

[39] Lantolf, J. (2007). Exploring the dialectic: An interview with James P. Lantolf. JALT Journal 29.1, 123.

[40] Lee-Thompson, L. (2008). An investigation of reading strategies applied by American learners of Chinese as a foreign language. Foreign Language Annals 41.4, 702-721.

[41] Leow, R. P. (1997). The effects of input enhancement and text length on adult L2 readers. Applied Language Learning 8.2, 151-182.

[42] Leow, R. P. (2002). Models, attention, and awareness in SLA: A response to Simard and Wong's (2001) Alertness, orientation and detection: The conceptualization of attentional functions. Studies in Second Language Acquisition 24, 113-119.

[43] Leow, R. P., H. Hsieh \& N. Moreno. (2008). Attention to form and meaning revisited. Language Learning 58.3, 665-695.

[44] Leow, R. P., \& K. Morgan-Short. (2004). To think aloud or not to think aloud: The issue of reactivity in SLA research methodology. Studies in Second Language Acquisition 26.1, 35-57.

[45] Nassaji, H. (2003). L2 vocabulary learning from context: Strategies, knowledge sources, and their relationship with success in L2 lexical inferencing. TESOL Quarterly 37.4, 645-670.

[46] Paribakht, T. S. (2005). The influence of first language lexicalization on second language lexical inferencing: A study of Farsispeaking learners of English as a foreign language. Language Learning 55.4, 701-748.

[47] Pressley, M. \& P. Afflerbach. (1995). Verbal protocols of reading: The nature of constructively responsive reading. Hillsdale, NJ: Lawrence Erlbaum Associates.

[48] Pritchard, R. (1990). The evolution of introspective methodology and its implications for studying the reading process. Reading Psychology: An International Quarterly 11, 1-13.

[49] Rao, Z., P. Y. Gu, L. J. Zhan \& G. Hu. (2007). Reading strategies and approaches to learning of bilingual primary school pupils. Language Awareness 16.4, 243-262.

[50] Richards, K. (2009). Trends in qualitative research in language teaching since 2000. Language Teaching 42.2, 147-180.

[51] Rosa, E., \& M. D. O'Neill. (1999). Explicitness, intake, and the issue of awareness. Studies in Second Language Acquisition, 21.4, 511-556.

[52] Russo, J. E., E. J. Johnson, \& D. L. Stephens. (1989). The validity of verbal protocols. Memory \& Cognition 17.6, $759-769$.

[53] Sanz, C., H. Lin, B. Lado, H. W. Bowden \& C. Stafford. (2009). Concurrent verbalizations, pedagogical conditions, and reactivity: Two CALL studies. Language Learning 59.1, 33-71.

[54] Smagorinsky, P. (2011). Thinking and speech and verbal data. Vygotsky and Literacy Research 2.3, 233-244.

[55] Stevenson, M., R. Schoonen \& K. de Glopper. (2007). Inhibition or compensation? A multidimensional comparison of reading.

[56] Upton, T. A. \& L. Lee-Thompson. (2001). The role of the first language in second language reading. Studies in Second Language Acquisition 23, 469-495.

[57] Watson, J. B. (1920). Is thinking merely the action of language mechanisms? British Journal of Psychology 11, 87-104. 
[58] Wesche, M. B. \& Paribakht, T. S. (2000). Reading-based exercises in second language vocabulary learning: An introspective study. The Modern Language Journal 84.2, 196-213.

[59] Yang, Y. (2006). Reading strategies or comprehension monitoring strategies. Reading Psychology 27.4, 313-343.

[60] Zhang, L., P. Y. Gu \& G. Hu. (2007). A cognitive perspective on Singaporean primary school pupils' use of reading strategies in learning to read English. British Journal of Educational Psychology 78.2, 245-271.

Patriann Smith is a doctoral candidate in the department of Literacy Studies at the University of South Florida and a resident of Tampa, Florida in the United States. In 2005, Patriann received her B.Sc. in Elementary Education from Andrews University, Berrien Springs, Michigan, and in 2010, earned her M.A. in Literacy Studies from the University of South Florida in Tampa, Florida.

Over the past ten years, Patriann has taught at elementary schools in Trinidad and St. Lucia and currently, she functions as a Graduate Teaching Assistant in the department of Literacy Studies at USF where she teaches literacy courses in assessment, writing, reading, literature, and vocabulary instruction. Patriann is also a Graduate Student Success fellow. Throughout her doctoral studies, Patriann's main emphasis has been on the linguistic foundations of multiculturalism as evidenced in her exploration of language learners' literacy processes, multilingual teachers' and teacher educators' linguistic differences in literacy teaching, and the methods associated with literacy research for language learners. Patriann continues to maintain a focused research agenda in these areas.

Ms. Smith is a member of and has presented at the annual meetings of the American Educational Research Association, Literacy Research Association, International Reading Education, and American Association for Teaching and Curriculum. Her work is soon to appear in Curriculum and Teaching Dialogue.

James R. King is a professor in the department of Literacy Studies at the University of South Florida and a resident of Florida in the United States. He received his B.A. in Elementary Education, English, and Mathematics and M.A.in Reading Education from Western Michigan University, Kalamazoo, Michigan. He then earned his Ed.D. in Curriculum and Instruction in Reading, Language Development, and Linguistics from West Virginia University, Morgantown, West Virginia and a post doctoral degree in Reading Recovery at Texas Woman's University, Denton, Texas.

James has taught at the University of South Florida for the past ten years. His publications include Uncommon caring: Learning from men who teach young children, published by Teachers College Press. His work has been published in Reading Research Quarterly, Journal of Literacy Research, Qualitative Studies in Education, Contemporary Ethnography, Journal of Adult and Adolescent Literacy, Reading Research and Instruction, as well as chapters in several edited volumes. His research interests include struggling readers in early grades through middle school, masculinities in elementary school contexts, qualitative research methodology, and queer and critical theorizing in educational contexts. Current research projects involve researching literate identities constructed in service-learning contexts.

Dr. King is a member of and has presented at the annual meetings of the American Educational Research Association, Literacy research Association, International Reading Association, and the American Reading Forum. 